Portland State University

PDXScholar

\title{
The influence of the transition plan in developing communication programs
}

Yuki Tanaka

Portland State University

Follow this and additional works at: https://pdxscholar.library.pdx.edu/open_access_etds

Part of the Disability and Equity in Education Commons, and the Secondary Education Commons Let us know how access to this document benefits you.

\section{Recommended Citation}

Tanaka, Yuki, "The influence of the transition plan in developing communication programs" (1991). Dissertations and Theses. Paper 4249.

https://doi.org/10.15760/etd.6133

This Thesis is brought to you for free and open access. It has been accepted for inclusion in Dissertations and Theses by an authorized administrator of PDXScholar. Please contact us if we can make this document more accessible: pdxscholar@pdx.edu. 
AN ABSTRACT OF THE THESIS OF Yuki Tanaka for the Master of Science in Education presented February 18, 1991.

Title: The Influence of the Transition Plan in Developing Communication Programs.

APPROVED BY THE MEMBERS OF THE THESIS COMMITTEE:

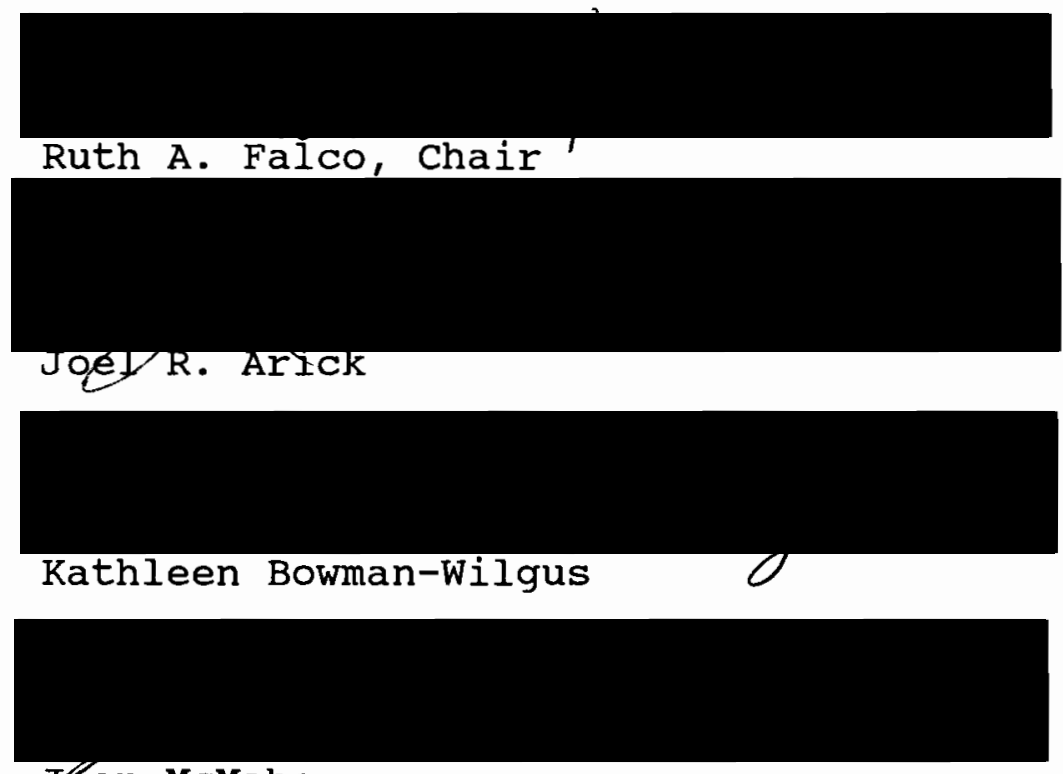

Iban McMahon

The transition of students with moderate to severe handicaps from school to work and adult life has become a principal concern of special education over the last decade. Despite of these attentions, there has been little attention to the need for including plans for the student's communication needs in his or her Transition Plan. Thus, it is important to study the relationship between the inclusion 
of a student's communication needs in his or her Transition Plan and the effectiveness of communication programs. The purpose of this study is to identify the relationship between the Transition Plan and the effectiveness of communication programs, considering the individual's functioning level, family involvement, and communication mode.

The 33 high school students with moderate to severe handicaps were selected as subjects, by the seven teachers who volunteered to participate in this study. The teachers identified them as having oral speech with less than threeword sentences, and/or using an augmentative communication system.

A survey instrument was designed to gather information on the individual's communication programs, Transition Plan, family involvement, communication mode, and functioning level. This survey instrument was developed by the investigator based on the previous research and studies. The survey contained following scales: functioning level scale, family involvement scale, communication effectiveness scale, communication mode, and Transition Plan. All survey questions were answered by the seven teachers participating in this study.

The results indicate a significant relationship between the effectiveness of communication programs and the inclusion of an individual's communication needs in his or her Transition Plan. Higher effectiveness scores were earned by the subjects who have the Transition Plan that includes their 
communication needs. Conversely, there was no significant impact on the effectiveness of communication programs by the individual's communication mode, or the degree of family involvement. However, the results indicate that there was a significant influence on the effectiveness of communication programs by the subject's functioning level.

The limitation with this study was the lack of a clear definition of a Transition Plan. This study was based on the assumption that all high school students with moderate to severe handicaps would have a Transition Plan. However, this was not always true. Some of the subjects did not have a Transition Plan yet. Another limitation with this study was the lack of a measurement of reliability. Unfortunately, none of the instructional aide could participate in this study, so there was no information available reading the reliability of the instruments. 


\title{
THE INFLUENCE OF THE TRANSITION PIAN IN DEVELOPING COMMUNICATION PROGRAMS
}

by

YUKI TANAKA

A thesis submitted in partial fulfillment of the requirements for the degree of

\author{
MASTER OF SCIENCE \\ in \\ EDUCATION
}

Portland state University

1991 
TO THE OFFICE OF GRADUATION STUDIES:

The members of the committee approve the thesis of Yuki Tanaka presented February 18, 1991.

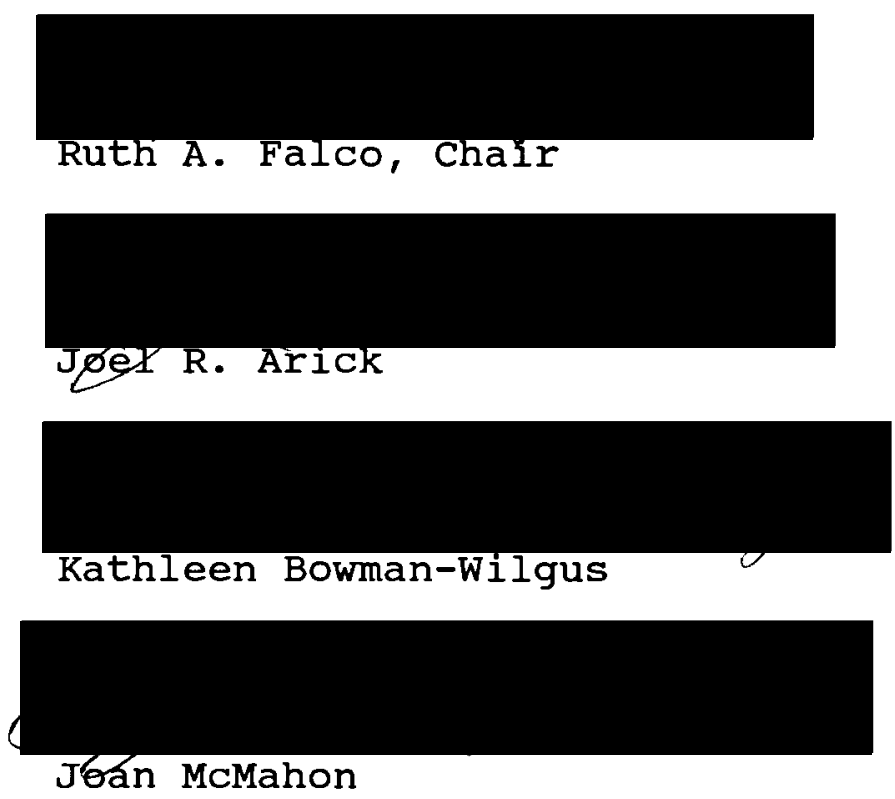

APPROVED:

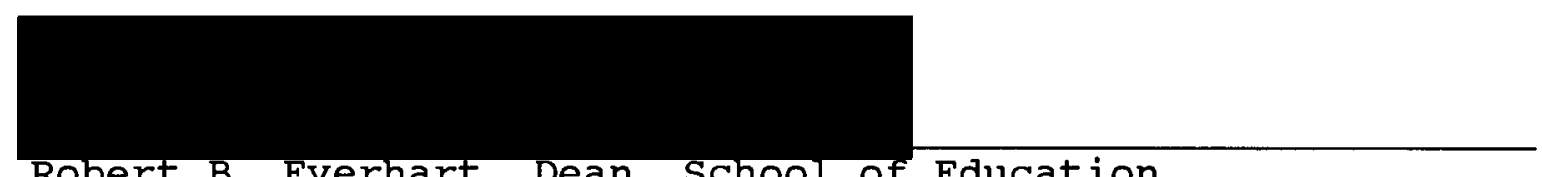

Robert B. Everhart, Dean, School of Education

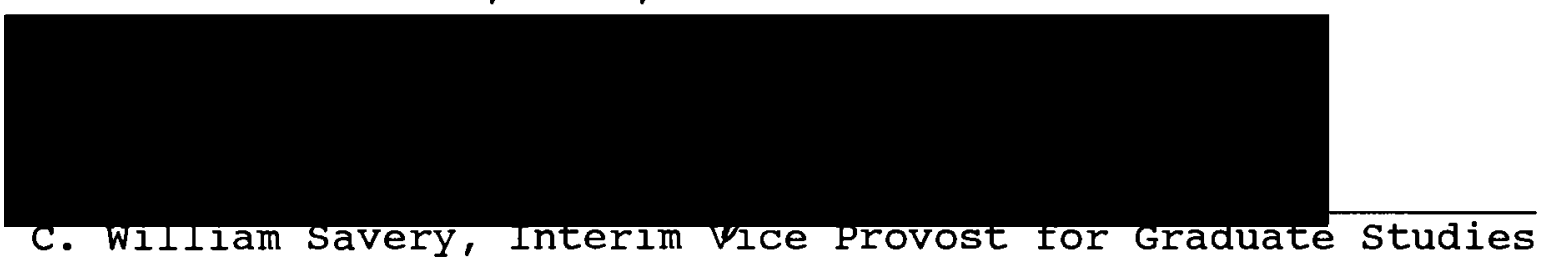
and Research 


\title{
ACKNOWLEDGEMENTS
}

I wish to express my sincere thanks and appreciation to the following pepole who provided professional and personal support during the writing of this thesis project:

\author{
Ruth A. Falco \\ Joel Arick \\ Jacki Freni-Rothchild \\ Kris Peason \\ and \\ All teachers \\ who gave of their time in this study
}


TABLE OF CONTENTS

PAGE

ACKNOWLEDGEMENTS . . . . . . . . . . . . . . . . . i ii

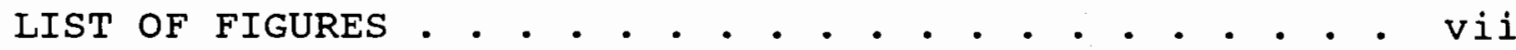
CHAPTER INTRODUCTION • • . • . . . . . . . . . . . 1

II STATEMENT OF THE PROBLEM . . . . . . . . . . . 3

Hypothesis . . . . . . . . . . . 7

Primary Hypothesis

Secondary Hypothesis

Operational Definitions . . . . . . . . 7

III REVIEW OF THE LITERATURE . • • • • • • • • • • 11

Transition Plan . . . . . . . . . . . 11

Characteristics of the Transition Plan Contents and Procedure of the Transition Plan

Augmentative Communication System . . . 14

Nature of Nonspeaking Populations Definition of Augmentative Communication The Candidacy for Augmentative Communication

Communication Programs Using

Augmentative Communication System . . . 18

Functional Communication Program

Factors for Effective Programing

IV METHODS . . . . . . . . . . . . . . . 23

Subjects . . . . . . . . . . . 23

Investigator

study subjects 
Instruments . . . . . . . . . . . 23

Functioning Level Scale

Family Involvement Scale

Communication Effectiveness Scale

Communication Mode

Procedure . . . . . . . . . . . . 27

Data Analysis . . . . . . . . . . 28

V RESULTS . . . . . . . . . . . . . . . 29

Descriptive Data . . . . . . . . . 29

Functioning Level Scale

Family Involvement Scale

Communication Effectiveness Scale

Communication Mode

Comparative Data . . . . . . . . . 31

Primary Hypothesis

Secondary Hypothesis \#1

Secondary Hypothesis \#2

Secondary Hypothesis \#3

other Findings . . . . . . . . . . 36

VI DISCUSSION . . . . . . . . . . . . 38

Effective Communication Programs . . . . 38

Study Limitation . . . . . . . . . 40

VII CONCLUSION . . . . . . . . . . . . . . 42

Summary of Subjects and Methods. . . . . 42

Summary of Results . . . . . . . . . 43

Recommendation . . . . . . . . . . 43

REFERENCES . . . . . . . . . . . . . . . . . . 45

APPENDIX

A FUNCTIONING LEVEL SCALE . . . . . . . . . . 48

B FAMILY INVOLVEMENT \& COMMUNICATION MODE . . . 51 
C COMMUNICATION EFFECTIVENESS SCALE . . • . . . . 54

D LETTER TO PROGRAM SUPERVISORS . . . . • • • • 57

E LETTER TO TEACHERS - . . . . . . . . . . . . 60

F INFORMED CONSENT FORM . . . . . . . . . . . . . 63 


\section{LIST OF FIGURES}

FIGURE

PAGE

1. Graph of Functioning Level Scale . . . . . 30

2. Graph of Family Involvement Scale . . . . 30

3. Graph of Communication Effectiveness Scale - 32

4. Graph of Communication Mode . . . . . . . 33

5. Graph of Functioning Level

and Transition Plan . . . . 37 
CHAPTER I

INTRODUCTION

Under Public Law 94-142, special education has been changed dramatically: all individuals with handicaps have been entitled to equal opportunities for education and access to community activities. However, once they leave the school system at age twenty-one, there is a significant shortage in community vocational and residential service programs. Consequently, the transition from school to work and adult life has become one of the growing concerns in special education and human services. The federal government has reacted to this problem by the Education for All Handicapped Children Amendments Public Law 98-199 in 1983 and Public Law 99-437 in 1986, authorizing funds for research, training, and demonstration projects in the area of transition (Everson \& Moon, 1987). In spite of those efforts, there are still significant problems in the process of the transition from school to adult life because adult services do not operate under entitlement procedures as does special education. Also, "appropriate" education does not always translate into paid employment opportunities once an individual leaves school (Everson \& Moon, 1987).

In addition to these problems, if individuals have very 
limited speech, and/or use augmentative communication systems, communication skills become a significant barrier in the process of the transition. Since communication is one of the most important basic skills needed to function in the community, individuals without adequate communication skills may not be able to function well. As a consequence, there may be a need to consider an individual's communication needs in the process of the transition from school to adult life in order to increase an individual's opportunity in the community. The purpose of this study is to identify the relationship between the Transition Plan and the effectiveness of communication programs, considering the individual's functioning level, family involvement, and the content of the individual's communication system. 
CHAPTER II

STATEMENT OF THE PROBLEM

In the past decades, the transition from school to work and adult life has been a growing concern in special education, including the availability of vocational training and post-school services. Actually, significant shortages in community-based vocational and residential services for individuals with severe handicaps have raised questions about the long-term effectiveness of special education (Hardman \& McDonnell, 1987; Fairweather, 1989). In addition to this, adult services for individuals with severe handicaps do not operate under entitlement procedures as does special education, so "integrated" education does not always translate into a community-based job and integrated living opportunities once an individual leaves school (Everson \& Moon, 1987). Several factors may influence the success of this transition. Since the Transition Plan (TP) is intended to prepare individuals with handicaps to move from school to work and adult life, it may have great influence on the quality of adult life for individuals with handicaps. Although TP does not have any clear legalized definition and formation, as does the Individualized Education Plan (IEP), TP usually determines the focus of the individual's curriculum, future environments, 
and the community training options (Transition committee on Visual Impaired, 1989). Mithaug, Martin, and Agran (1987) noted that instructional procedures during school will make a difference in an individual's success in work and other environments after school. Therefore, there may be great influence on an individual's adult life as to whether TP includes instructional guidelines that plan to maximize his or her independence and competence in the community.

A critical factor that may effect an individual's success in post-school life is the effectiveness of his/her communication skills. Without adequate communication skills, no one can be successful in our society. For example, individuals need to know how to interact appropriately with their employer and co-workers in order to find and maintain a job in the community. Especially, individuals who have very limited oral speech ability, or who do not have any means of oral speech ability, may have great difficulty in functioning in the community. Thus, it may be important for individuals with limited communication ability to acquire some kinds of effective communication skills that allow them to function in the community when they are in school. Since the related services, including speech and language services, are seldom available after leaving the school system, it is very important for individuals with handicaps to learn effective communication beforehand. At the same time, the school system has the responsibility to provide needed services to these 
individuals in order to maximize their success after the school system.

As described before, the adult services for individuals with handicaps do not operate under entitlement procedures, as opposed to those procedures for individuals in school. As a result, families are the main support system for individuals with handicaps after they leave the school system. Therefore, it is very important to have the individual's family involved in the process of transition from school to adult life. Stiea and Bauer (1985) stressed the importance of family involvement for positive and effective change of their children's lives. other studies have also noted that family involvement plays a very critical role in successful transition from school to adult life (Rusch, Chadsey-Rusch, \& Lagomarichino, 1987; Sileo, Rude, \& Luckner, 1988; Polloway, Patton, Payne, \& Payne, 1989).

In addition to family involvement, an individual's communication mode may have great influence on their success in post-school life, especially for individuals with very limited oral speech, or without oral speech ability (Miller \& Allaire, 1987; Musselwhite \& St. Louis, 1988). For example, in the community at large, very few people know sign language, so individuals who use sign as their communication mode may have great difficulties in finding and maintaining a job in the community. Also, individuals who use picture cards or communication boards have very limited vocabularies, so they 
can only communicate to others in the certain settings in which their vocabularies in the system can be used. Considering these factors, the communication mode does seem to play a very important role in the individual's post-school life.

Another factor that has a great influence on the success of an individual's post-school life is the individual's physical and cognitive functioning level. The individuals with a lower functioning level are less independent than individuals with a higher functioning level, so they have more difficulties in finding and maintaining a job in the community. Also, the programs for the lower functioning level individuals are often less practical. For example, an individual with lower functioning level learns how to request food in the classroom without any natural sequence, rather than learning during lunch time in the cafeteria, or in community settings. Thus, there is a need to compare how an individual's functioning level effects his/her programs.

Based on these aspects, this study will look at the relationship between the Transition Plan and the effectiveness of communication programs. Involved in the effectiveness of communication programs are family involvement, the individual's communication mode, and his or her level of functioning. The main focus of this study is whether the inclusion of an individual's communication need in his or her Transition Plan makes any difference in his or her 
communication programs, especially in their effectiveness.

$$
\text { HYPOTHESIS }
$$

\section{Primary Hypothesis}

There is no significant difference between the effectiveness of communication programs for individuals with Transition Plans that include their communication need, and the effectiveness of communication programs for individuals with Transition $\mathrm{Plans}$ that do not include their communication needs.

\section{Secondary Hypothesis}

1) An individual's communication mode has no significant impact on the effectiveness of communication programs.

2) There is no significant impact on the effectiveness of communication programs by the programs with high family involvement and the programs with low family involvement.

3) An individual's functioning level has no significant impact on the effectiveness of communication programs.

OPERATIONAL DEFINITIONS

For the purpose of this study, the following definitions were set.

Communication Programs. Communication programs are defined as written programs that require the use of communication skills. Thus, any programs that stress communication skills would be applicable in this study. 
The effectiveness of communication programs.

The effectiveness of communication programs is defined as the number of the following criteria met by the individual's current communication programs (as described by the classroom teachers on a written survey sheet): 1) the intelligibility of the system; 2) the individual's independent operation of the system; 3 ) the mobility of the system; 4) the variety of sites used in the programs; 5) the variety of conversation partners in the programs; 6) the variety of sites where an individual can initiate the use of the system; 7) the variety of sites where an individual can use the system spontaneously and consistently; and 8) the variety of purposes for an individual's use of communication.

Transition Plan. The Transition Plan that includes an individual's communication need is defined as a written Transition Plan that includes at least one of the followings: 1) a plan for the development and/or maintenance of a communication system; 2) a plan for programs to develop the use of the communication systems; 3 ) the designation of responsibility for the maintain of the communication system required after achool; and 4) plans for funding to meet an individual's communication need.

Communication mode. A communication mode is defined as having two categories: unaided and aided modes. The unaided communication mode is defined as symbols and symbol systems that do not require any aids or devices, but use only the 
sender's face, head, hands, and other parts of the body (Musselwhite \& st. Louis, 1988). The four categories of unaided mode used in this study are as follows: 1) gestures with vocalization - a combination of non-linguistic physical movements and vocalization; 2) gestures without vocalization non-linguistic physical movements with no vocalization ability; 3) sign - any physical movement with a linguistic element of meaning; and 4) oral speech with less than threeword sentences.

on the other hand, the aided communication mode is defined as symbols and symbol systems that require some type of external assistance, aid or device (Musselwhite \& st. Louis, 1988). Five categories of aided modes are used in this study: 1) picture cards - cards with drawings or photographs; 2) communication board - a board with a set of drawings, photographs, words, or other symbols; 3) communication book a book with a set of drawings, photographs, words, or other symbols; 4) electric device with voice - a variety of electric devices with a speech system; and 5) electric device without voice - a variety of electric devices without a speech system.

Family involvement. The family involvement refers to the corporation of the family and school. The family involvement used in this study listed the following criteria: 1) the caregiver owns the system; 2) the caregiver selects vocabulary for the system; 3) the caregiver can change vocabulary and make changes in the system easily; 4) the caregiver can 
maintain the system technically and economically; and 5) the caregiver uses the system to communicate with the subject.

Functioning level. An individual's functioning level is defined as including the following: independent functioning, physical development, language development, understanding of the concepts of numbers and time, economic activity, domestic activity, vocational activity, self-direction, understanding of responsibility, and socialization (AAMD ad hoc Committee on the Adaptive Behavior Scale, 1975). 
CHAPTER III

REVIEW OF THE LITERATURE

TRANSITION PLAN

\section{Characteristics of the Transition Plan}

The purpose of a Transition Plan is to prepare an individual with handicaps to move from school to work and adult life. As Bellamy and Horner (1987) noted, the goals of the Transition Plan for individuals with handicaps are to find meaningful employment, to select a place to live, and to get the support that will maintain and continue the personal development achieved during their school years. Mithaug, Martin, and Agran (1987) stated that a Transition Plan is a preparation for post-school life. In spite of the interest and efforts in studying and researching transition services, there has been still no clear definition or legalized procedures for the Transition Plan. There has been some legal effort in the area of transition, though. For example, the federal government has authorized funds for research, training, and demonstration projects in the area of transition by the Education for All Handicapped Children Amendments Public Law 98-199 in 1983 and P.L. 99-437 in 1986 (Everson \& Moon, 1987). Accordingly, each state and agency has developed 
a variety of models for the transition process. The oregon Department of Education has published a transition guide book in 1989 for students with visual impairments (Transition Committee on Visual Impaired, 1989). In this guide book, the Transition Plan is described as essential for secondary-aged students with handicaps to bridge the gap between school and adult life, including such matters as continuing education, work programs, residential services, federal and state income support, community mobility, estate planning, recreation, socialization, and issues of greater independence within the community.

\section{Contents and Procedure of the Transition Plan}

Basically, the contents and procedures of the Transition Plan vary according to the states and agencies. According to Polloway, Patton, Payne, \& Payne (1989), the Transition Plan usually consists of two domains: life domains and support domains. Life domains include daily living, leisure and recreation, vocational and other training, personal and social matters, and community. On the other hand, support domains cover referrals to adult services, such as financial support agencies, emotional/physical health support agencies, and so forth. Usually, those domains in the Transition Plan determine the focus of the individualized curriculum, future environments, and community training options (Transition Committee on Visually Impaired, 1989). Therefore, programs that have implemented the Individualized Education Plan should 
be related to the Transition Plan. Rusch, Chadsey-Rusch, and Lagomarichino (1987) listed four guidelines for developing programs to support the Transition Plan: 1) community referenced; 2) integrated; 3) longitudinal; and 4) communitybased. Also, Polloway, Patton, Payne, and Payne (1989) defined six features of transition-oriented programs: 1) ageappropriate; 2) comprehensive; 3) relevant; 4) empirically and socially valid; 5) flexible; and 6) community-based.

According to Wehman, Wood, Everson, Goodwyne, and Conley (1988), the focal point of the transition process is the development of a formal written plan for each student. They also listed eight basic steps for implementing the Transition Plan: 1) identify students for formal transition planning; 2) identify school personnel and adult service personal to serve as members of the Transition Plan team; 3) identify adult service agencies and organizations who will provide adult services to the target student; 4) gather relevant information on each student targeted for transition planning prior to the meeting; 5) schedule the meeting; 6) conduct the meeting; 7) conduct a follow-up of goals and objectives set at the meeting at six-month interval; and 8) schedule an exit meeting for students and/or parents of students.

The individual's family plays a very critical role in the process of the Transition Plan. As Halpern (1987) noted, the need for family involvement in the Transition Plan derives from the likelihood that parent involvement will have a 
significant impact on the kinds of opportunities made available to their children. Sileo, Rude, and Luckner (1988) also stated that family participation in the process of transition planning is essential to ensure participatory decision making and continuity in career/vocational training and placement; independent living arrangements; personal care and medical managements; and the financial considerations, guardianship or advocacy needs of the individuals. Therefore, family involvement is one of the most important aspects in the process of the Transition Plan.

Falvey (1986) noted that one of the most essential skills necessary to participate in community-based activities, including vocational, domestic, and leisure, is the ability to communicate. Without adequate communication skills, no individual can be successful in the community, so it is very critical to identify an individual's communication needs in the process of developing the Transition Plan, in order to maximize an individual's success in post-school life.

\section{AUGMENTATIVE COMMUNICATION SYSTEM}

\section{Nature of Nonspeaking Populations}

The majority of individuals with handicaps have a difficulty in communicating to others, especially individuals who do not have any physical ability to produce speech. Those individuals who have no effective means of communication due to severe physical and/or linguistic limitation have been 
defined as nonspeaking populations (Russel, 1984). Although some of these individuals can produce a limited amount of speech, the intelligibility of their exhibited speech is not adequate for communication, or is not enough to function in society. Musselwhite and St. Louis (1988) have identified five categories of basic impairments which influence communication: 1) cognitive impairment - mental retardation; 2) sensory impairment - deafness, blindness, and deaf-blind; 3) neurological impairment - cerebral palsy, aphasia, apraxia, dysarthria, progressive disorders, and dysphonia from vocal folds paralysis; 4) emotional impairment - autism, elective mutism and childhood psychosis; and 5) structural impairment glossectomy and laryngectomy. Since many nonspeaking individuals exhibit multiple impairments contributing to communication disorders, these categories are not mutually exclusive. For example, cerebral palsy may often accompany mental retardation. Consequently, it is necessary to find another communication methods for these nonspeaking individuals to learn effective communication skills in order to function in the society.

\section{Definition of Augmentative Communication}

In 1981, the American Speech-Language-Hearing Association (ASHA) has defined the term augmentative communication system as the total functional communication system of an individual whose speech is not fully functional. This system is made up of: 1) communication technique to transmit ideas; 2) symbol 
set or system to represent ideas or concepts; and 3) communication/interaction behavior in which ideas are received and understood (American Speech-Language-Hearing ad hoc Committee on Communication Processes and Nonspeaking Persons, 1981). Generally, the augmentative communication system can be divided into two basic categories: an unaided and aided system. The term "unaided" refers to all techniques which do not require any physical aids, and the systems include manual, gestural, sign or facial communication as well as oral speaking (American Speech- Language-Hearing ad hoc Committee on Communication Processes and Nonspeaking Persons, 1981). These unaided systems are often limited in scope, because they are functional only between individuals who know the meaning of the gesture or sign system (Russel, 1984).

The term "aided", however, refers to all techniques where some types of physical object or device is used, such as communication boards, charts, and mechanical or electronic aids (American Speech-Language-Hearing ad hoc Committee on Communication Processes and Nonspeaking Persons, 1981). The aided systems usually impose barriers to effective communication, in that they often interfere with conversational interaction between the user and his or her conversational partner, in such ways as eye-contact, turntaking, or other interactions (Russel, 1984). Additionally, it may be hard for nonspeaking individuals to acquire pragmatic functions by means of this system (Reichle \& Yoder, 
1985). Based on these aspects, the selection between the unaided or aided system is often determined by the nature of the individual's impairment level and ability.

\section{The Candidacy for Augmentative communication}

In order to use an augmentative communication system, nonspeaking individuals must have the certain abilities to use them. Shane and Bashir (1980) have developed a branchingtype decision matrix to determine the individual's candidacy for the augmentative communication system. Their decision matrix consists of ten categories: 1) cognitive factors sensory-motor intelligence, mental age, and the ability to represent thoughts through pictures; 2) oral reflex factors rooting, gag, bite, suckle/swallow, or jaw extension reflex; 3) language and motor speech production factors receptive/expressive discrepancy; 4) motor speech contributing factors - eating problems, apraxia, or drooling; 5) production contributing factors - unintelligible speech and frustration; 6) emotional factors - selective mutism; 7) chronological age factors - under 3 years or over 5 years; 8) previous therapy factors - appropriateness and progress; 9) previous therapy/contributing factors - motor, oral, or vocal imitation; and 10) implementation factors/environment - family acceptance (Shane \& Bashir, 1980). The decision to elect an augmentative communication system must be carefully made, since the augmentative communication system has a grreat impact on the individual's life as well as the interaction and 
relationship between the individual and his or her communication partner.

\section{COMMUNICATION PROGRAMS USING \\ AUGMENTATIVE COMMUNICATION SYSTEM}

\section{Functional Communication Program}

Over the past decade, many studies have been done to develop communication program and to improve nonspeaking individuals' communication skills by using an augmentative communication system. In spite of these efforts, few nonspeaking individuals use their communication systems in their daily living situations. According to warren and Rogers-Warren (1985), a child learns the function of language through experiencing the consequence of its use in the natural environments. In addition, language is embedded in special participation in the beginning states of language development. Thus, nonspeaking individuals need to be taught the use of an augmentative communication system in natural settings.

Harris (1982) noted that the goal of any training program for nonspeaking individuals should be to train them to use the augmentative communication system while socially interacting in their environment. Considering this factor, Glennen and Calculator (1985) studied the pragmatically based language intervention approaches to developing communication programs. Their study targets training one specific type of initiation, request for objects, and incorporated lexical training within a motivating communicative context. They concluded that the 
pragmatic approach to training fanctional communication may facilitate generalization of new communication skills to other contexts. Based on their study, they recommended that nonspeaking communication training should be carried out during naturally structured activities in which the child is motivated to communicate.

Other studies also have been done to develop functional communication programs. Kaiser, Alpert, and Warren (1987) suggest combining ecological information and individual assessments in order to make a plan for training. They also recommend using milieu teaching. Milieu teaching refers to the communication training procedures that use controlled environments as opportunities for teaching functional communication which naturally occurs, and is occasioned by the individual's interest in the topic to which training will relate (Kaiser, Alpert, Warren, 1987). This training contains four main procedures: 1) child-directed modeling that includes building turntaking skills, training generalized imitation skills, establishing a basic vocabulary, and participating in conversations that occur outside the training context; 2) the mand-model procedure that includes generalization of language skills from one-to-one training sessions to the classroom; 3) the time-delay procedure that establishes environmental stimuli other than verbally presented models and mands as cues for verbalization; and 4) the incidental teaching procedure that is used to elicit 
language about some reinforcer specified by the student. The functionality of programs is addressed as element in this training. They are such as arrangement of the environment, prerequisite teaching skills, data collection, and evaluation. Although milieu language training requires many kinds of teaching techniques and preparation to teachers and trainers, this method is very effective in developing functional communication programs for the nonspeaking individuals.

\section{Factors for Effective Programing}

There are three essential factors in developing functional communication programs: 1) communication mode selection; 2) the selection of system design; and 3) vocabulary selection. The mode of communication is defined as a major channel form of communication, such as speech, gesture, and writing (Musselwhite \& st. Louis, 1988). Silverman (1980) stated that the communication mode has a great impact on a nonspeaking individual's ability to encode and transmit messages. Since each communication mode is very different in flexibility, efficiency, and the variety of communication partners, the selection of modes is very critical to the success of an individual's use of the augmentative communication system.

Another essential factor is the selection of system design. As Musselwhite and st. Louis (1988) noted, there are two main factors in designing communication system: 1) the individual's physical and communicative abilities; and 2) the 
individual's needs in various settings. According to Mirenda (1985), the most important factors to consider in designing are the individual's visual scanning skills, visual attending skills, motor planning skills, and motor-coordination skills.

The third key factor in developing functional programs is vocabulary selection. Charlson (1981) states that the vocabularies selected by teachers, parents, speech-language pathologists, and others usually consist of words that the adult wanted or needed to have the child communicate, rather than those that would have emerged out of the activities and interests of the child. As a result, the child may fail to use the system. Mirenda (1985) listed six major components of vocabulary selection based on the ecological inventory approach: 1) to determine the current and subsequent school and community environments in which the individual functions; 2) to conduct on-site analysis of the communication requirements of nondisabled persons during actual activities in those environments; 3 ) to conduct on-site inventories of nonspeaking individuals related to the same activities and environments; 4) to conduct discrepancy analysis to determine the communication deficits and needs of nonspeaking individuals; 5) to interview significant others regarding communication needs; and 6) to create instructional adaptations, such as picture communication books, addressing their needs.

Since the effectiveness of communication skills is 
essential factor to function in society, the effective communication programs is an essential to successful transition from school to adult life. However, there has been little attention to the need for including plans for an individual's communication needs in his or her Transition Plan. Thus, it is important to study the relationship between the inclusion of an individual's communication need in the Transition Plan and the effectiveness of communication programs. 
CHAPTER IV

METHODS

SUBJECTS

\section{Investigator}

The chief investigator in this study was a female graduate student in a special education master's program, focusing on individuals with severe handicaps.

\section{Study subjects}

Thirty-three subjects for this study were high school students selected by seven teachers who volunteered to participate in this study. The teachers identified students as having oral speech with less than three-word sentences and/or using an augmentative communication system. The agerange of subjects was from thirteen to twenty-one years. Subjects were currently attending high school programs in one of the following school district in oregon: Portland, Hillsboro, Multnomah Education Service District, and Yamhill Education Service District.

INSTRUMENTS

A survey instrument was designed to gather information on the individual's communication programs, Transition Plan, 
family involvement, communication mode, and functioning level. The survey instrument was developed by the investigator based on the previous research and studies. All survey questions were answered by the seven teachers.

\section{Functioning Level scale}

The individual's functioning level is scaled by answering yes/no questions. There are fifteen items to answer, and each 'yes' answer is given one point. (See Appendix A for a copy of this scale.) All items on the scale are based on AAMD Adaptive Behavior Scale for Children and Adults: 1974 Revision (AAMD ad hoc Committee on the Adaptive Behavior Scale, 1975) and developed by the investigator. The purpose of this scale is to identify each subject's independent functioning level. The items in this scale contain the following areas: self feeding, self toileting, independent mobility, money handling concept of numbers, minor purchasing, writing, reading, time concept, attention, leisure, awareness of others, turntaking, participation in the group activities, and refraining from self-stimulation.

\section{Family Involvement scale}

The family involvement scale is developed by the investigator, focusing on parents/caregiver involvement in communication programing. A five-item scale is listed on the survey sheet: 1) the ownership of communication system; 2) the participation in selecting vocabulary for the system; 3 ) 
changing vocabulary in the system; 4) the maintenance of the system; and 5) the use of the system at home. (See Appendix B for a copy of this scale.) All items are answered by "yes" or "no" and each "yes" answer given one point. In addition, there is one more question asking frequency of contact between the teacher and student's family. There are five selections: daily, weekly, monthly, once per two month, and once a year.

\section{Communication Effectiveness Scale}

The effectiveness of communication programs is scaled by eight items with a possible thirty-nine points. (See Appendix C for a copy of this scale.) These items are developed by the investigator, being based on a review of relevant professional literature. This scale is to determine the effectiveness of the student's communication programs by checking the contents of programs and functionality of his or her communication system. Item 1 through 3 are questions regarding the communication system: intelligibility of the system and the individual's independence in using and carrying the system. Item 4 is to identify the variety of sites used in communication programs. Six sites are presented to choose from: activities in the special classroom, integrated activities outside of special classroom, activities in the community, vocational training in the classroom and school, vocational training in the community, and home. Item 5 through 7 are to identify the individual's functioning level in using his or her communication system. Item 5 is to 
identify his or her independence in communicating with following people: special education teacher, regular classroom teachers, instructional aides, peer tutors, other peers in his/her classroom, others in the school, vocational trainers/supervisors, co-workers at work site, family members, familiar people in the community, and unfamiliar people in the community. Item 6 and 7 are to determine his or her initiative, and spontaneous and consistency use of the system in the following sites: special classroom, other places in the school, work site, home, familiar places in the community, and new places in the community. Item 8 is to identify purposes of an individual's communication: requesting items and events, rejecting and/or protesting, asking questions, stating comments, getting information, and expressing feeling and thoughts.

\section{Communication Mode}

Nine categories of communication modes were listed on the survey sheet: 1) gesture with vocalization; 2) gesture without vocalization; 3) sign; 4) oral speech with less than threeword sentences; 5) picture cards; 6) communication board; 7) communication book; 8) electric device with voice; and 9) electric device without voice. (See Appendix B for a copy of this section.) classroom teachers were asked to identify the subject's primary mode. 


\section{PROCEDURE}

The investigator contacted special education supervisors in the following school districts in oregon by mail: Portland, Beaverton, Tigard, Hillsboro, Clackamas Education Service District, Multnomah Education Service District, and Yamhill Education Service District. (See Appendix D for a copy of the letter to supervisors.) Four out of seven districts responded to this request and gave the written permissions for direct contact to the teachers for voluntary participation in the study. Lists of teachers' names and telephone numbers to contact were provided by the supervisors from the following districts: Portland, Hillsboro, Multnomah Education Service District, and Yamhill Education Service District. Letters were sent to each of 11 teachers listed by each supervisor, and 7 of them responded with agreement. (See Appendix E for a copy of the letter to teachers.)

After receiving agreements for voluntary participation by the teachers, the date of the interview was set up between the teacher and the investigator. During the interview, the teacher and the investigator selected subjects who have oral speech with less than three-word sentences and/or use an argumentative communication system. In the beginning of the interview, the investigator explained the purpose of this study, then the investigator asked her or him to sign an informed consent form. (See Appendix $F$ for a copy of the informed consent form.) Then, the investigator gave one 
survey to the teacher. The teacher and the investigator went though the survey for one subject, as an example. Later, the teacher completed surveys for the other subjects.

At the interview, the investigator asked the teacher whether the investigator could ask an instructional aide to voluntarily participation in this study. Unfortunately, none of instructional aides participated in this study, so it was not possible to study the inter-rater reliability of instruments.

\section{DATA ANALYSIS}

Frequency distributions were calculated for the following variables: Transition Plans that include the individual's communication needs and those that do not; family involvement scores; individuals' communication modes; and individuals' functioning levels. Also, means and standard deviations were calculated for the effectiveness scores for those who have communication needs in their Transition Plans and those who do not; for each category of communication mode; for each category of family involvement; and for each functioning level. 
CHAPTER V

RESULTS

The 33 students were identified by the seven teachers as individuals who have oral speech with less than three-word sentences and/or use an augmentative communication system. All surveys were answered completely without any missing answer. All statistical operations were performed with the SYSTAT: The System for statistics (Wilkinson, 1987) computer program.

\section{DESCRIPTIVE DATA}

\section{Functioning Level scale}

The Functioning Level Score mean for the 33 subjects was 6.21 with a standard deviation of 3.59 out of a possible low to high score of zero to 15. A frequency distribution of Functioning Level score is shown in Figure 1.

\section{Family Involvement Scale}

The Family Involvement Scores for the 33 subjects had a mean of 1.18 with a standard deviation of 1.66 . The family involvement scale had a possible low to high score of zero to 5. A frequency distribution of Family Involvement score is shown in Figure 2 . 


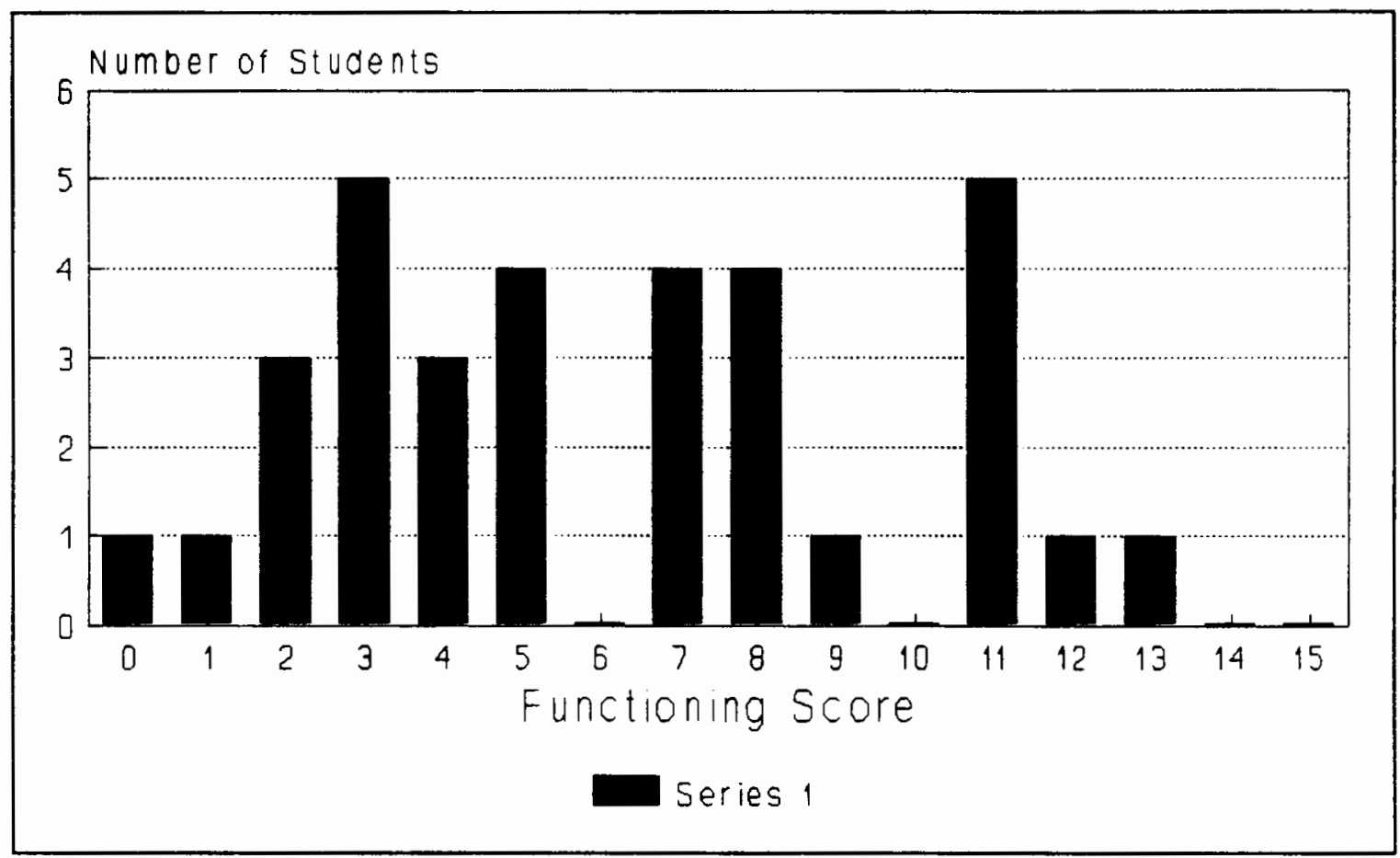

Figure 1. Graph of Functioning Level Scale

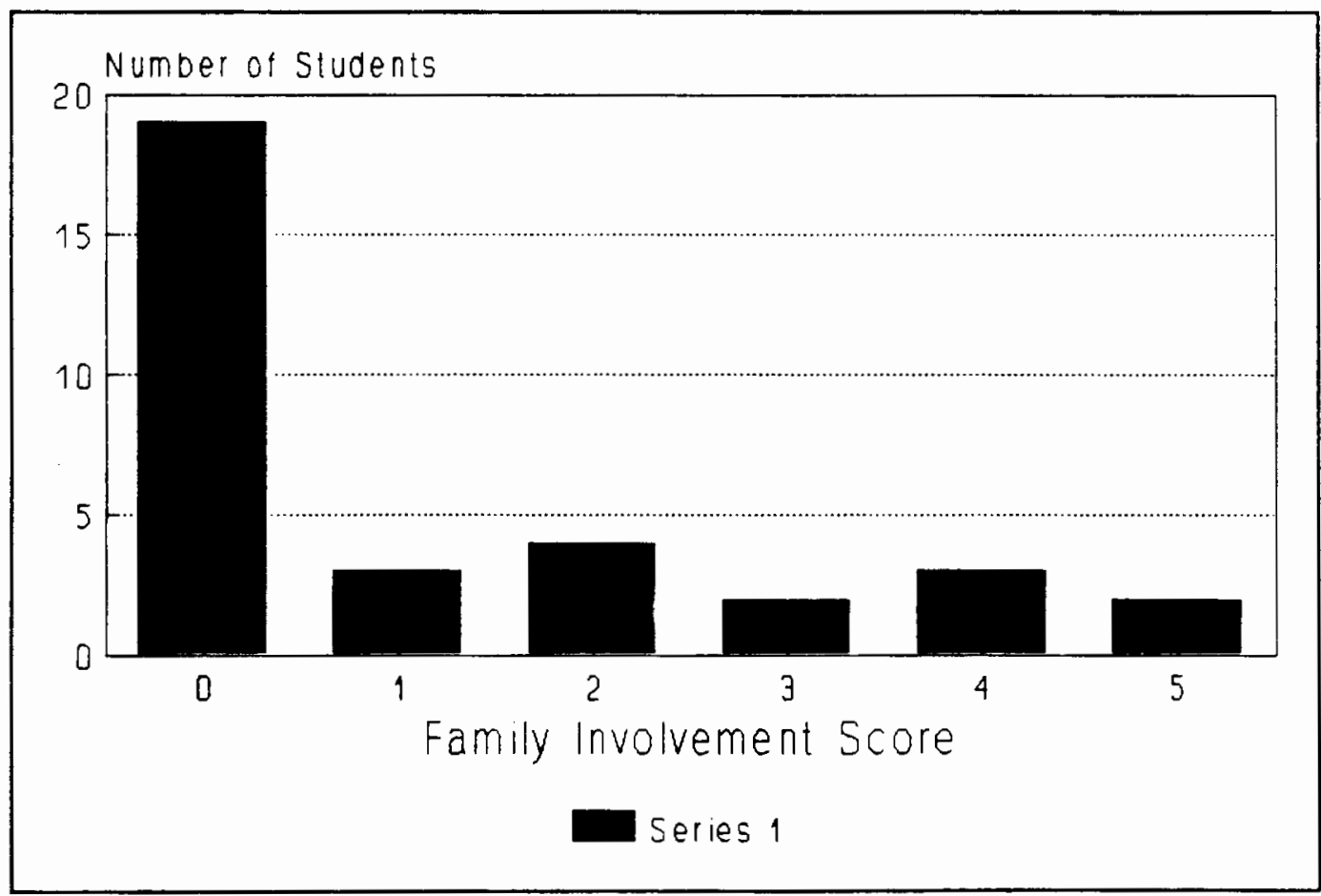

Figure 2. Graph of Family Involvement Scale 
Communication Effectiveness Scale

The effectiveness of communication programs was scaled by the communication effectiveness scale that had a possible low to high score of zero to 39. The communication Effectiveness Scores for the 33 subjects had a mean 13.97 with a standard deviation of 10.46. A frequency distribution of the communication effectiveness scale is shown in Figure 3.

\section{Communication Mode}

A frequency distribution of communication mode is shown in Figure 4. Twenty-three subjects out of thirty three $(81.8 \%)$ were using unaided communication modes and ten subjects $(18.2 \%)$ were using aided communication modes.

\section{COMPARATIVE DATA}

\section{Primary Hypothesis}

There is no significant difference between the effectiveness of communication programs for individuals with Transition Plans that include their communication needs and the effectiveness of communication programs for individuals with Transition Plans that do not include their communication needs.

A comparison was made between the subjects with the Transition Plan that include their communication needs and the subjects who do not have the Transition Plans that include their communication needs by using a T-Test.

The subjects with the Transition Plan that include their 


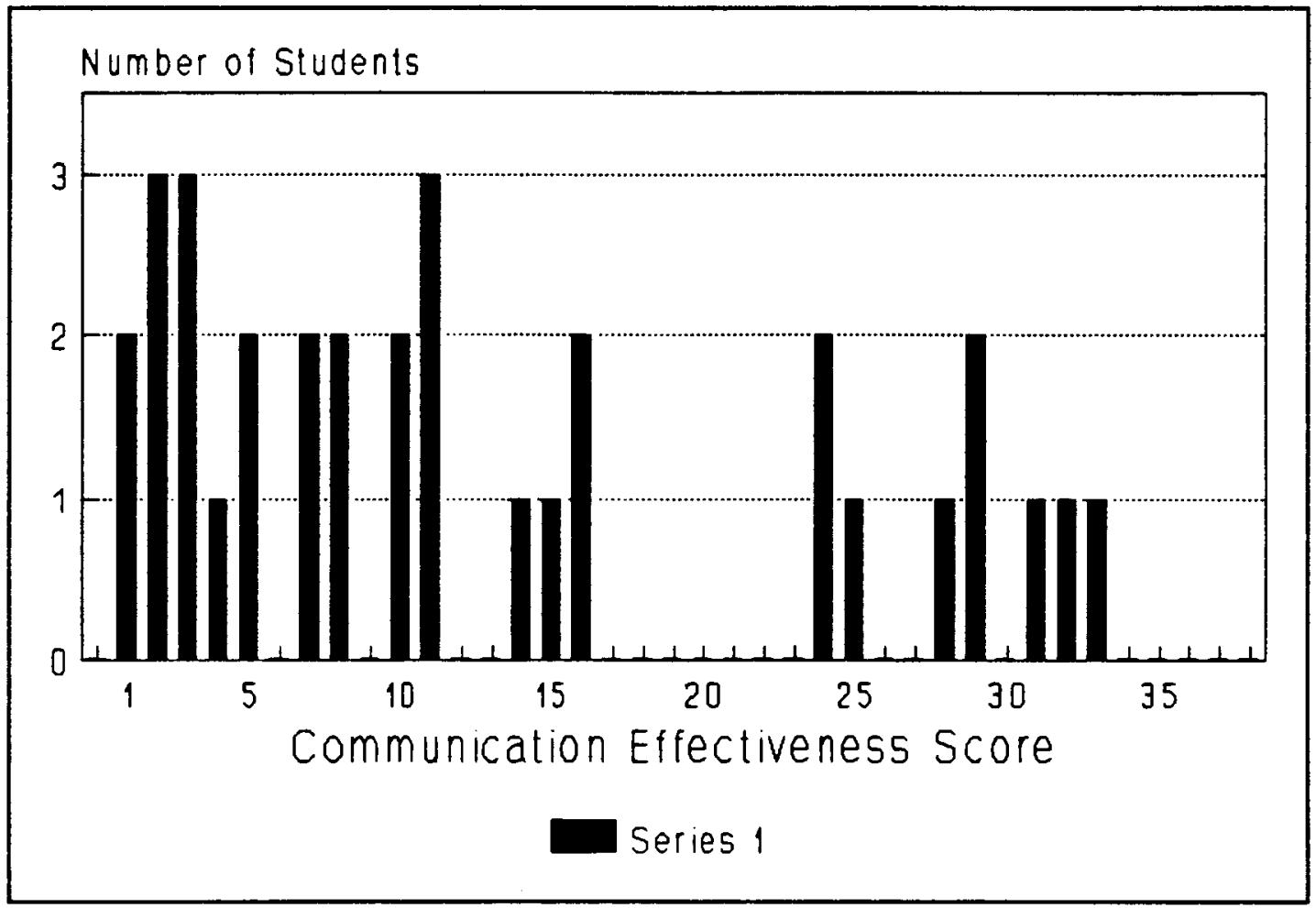

Figure 3. Graph of Communication Effectiveness Scale 


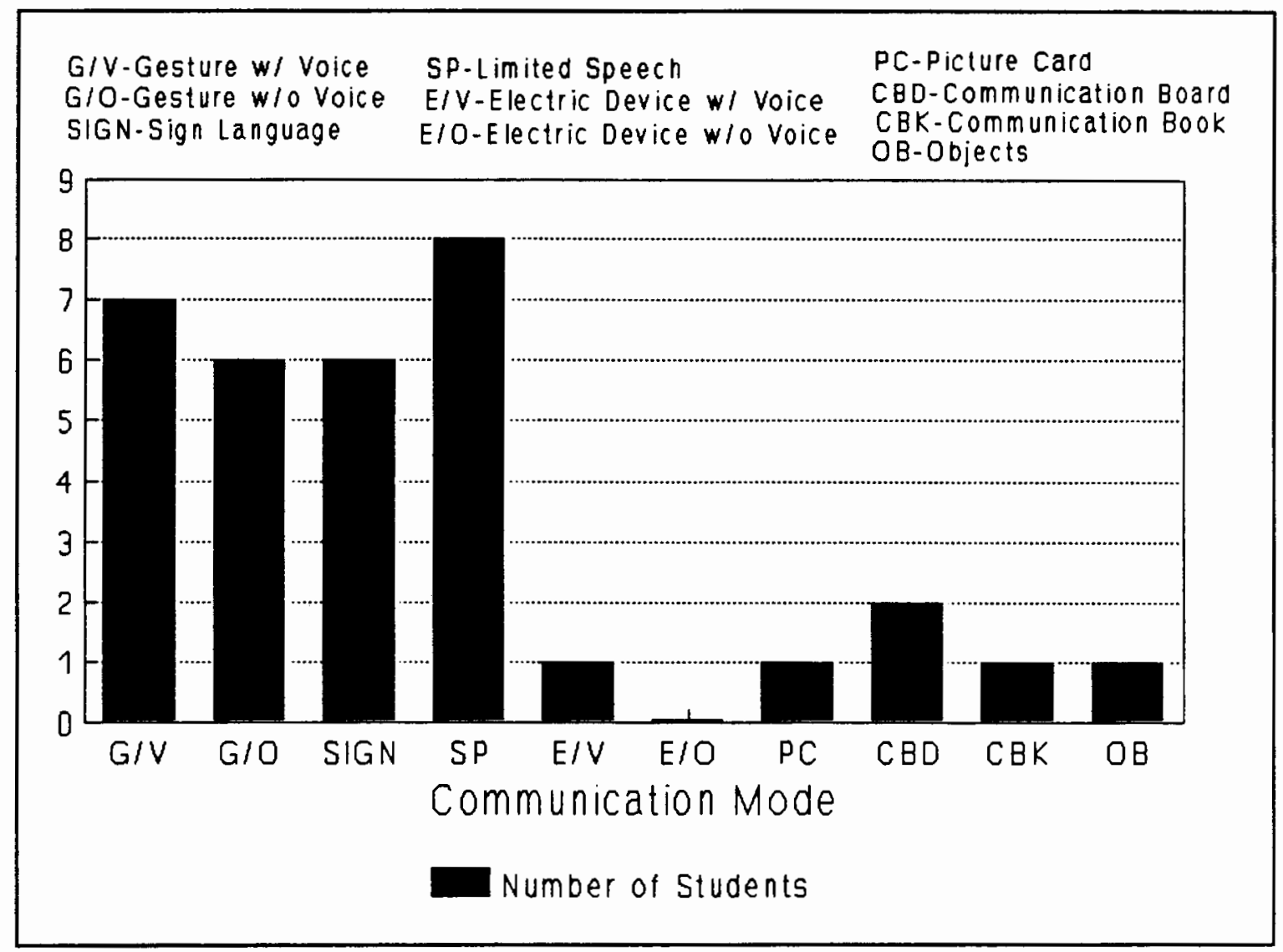

Figure 4. Graph of Communication Mode 
communication needs were 12 out of 33 subjects. Their Communication Effectiveness score mean was 20.5 with a standard deviation of 10.06. The subjects who do not have the Transition Plan that include their communication needs were 21 subjects and their Communication Effectiveness Score mean was 10.23 with a standard deviation of 8.89 . The subjects with the Transition Plan including their communication needs had significantly higher communication Effectiveness Scores than the subjects who do not have the Transition Plan that include their communication needs at $t(31)=3.04 ; p \leq .005$

These results indicate that there is a significant difference between the effectiveness of communication programs for the subjects with the Transition Plan that include communication needs and the effectiveness of communication programs for the subjects who do not have the Transition Plan that include communication needs.

\section{Secondary Hypothesis \#1}

An individual's communication mode has no significant impact on the effectiveness of communication programs.

A comparison was made among each categories of the subjects' communication modes by the Communication Effectiveness scores. For the testing, the communication Effectiveness Scores were collapsed into five groups based on their frequency distribution, and these five groups were compared by using a pearson chi-square. 
The result was $\chi 2(32)=30.52 ; \mathrm{p}>.05$. Thus, there was no significant impact on the effectiveness of communication programs by the individual's communication mode.

Secondary Hypothesis \#2

There is no significant impact on the effectiveness of communication programs by the programs with high family involvement and the program with low family involvement.

The Family Involvement Scores from zero to five were compared by the communication Effectiveness scores, using a pearson chi-square test. For the test, the communication Effectiveness Scores were collapsed into five groups based on their frequency distribution.

The result of the test was $\chi^{2}(20)=19.66 ; p>.05$. Thus, there was no significant impact on the effectiveness of communication programs by the degree of family involvement.

Secondary Hypothesis \#3

An individual's functioning level has no impact on the effectiveness of communication programs.

Using a statistical test, a pearson chi-square, a comparison was made among the Functioning Level scores for the Communication Effectiveness scores. In the process of the testing, the Communication Effectiveness scores were collapsed into five groups.

The result was $\chi^{2}(16)=35.34 ; \mathrm{p} \leq .005$. This result indicated that subjects with higher Functioning Level scores 
have higher Communication Effectiveness scores. Thus, there is a significant impact on the effectiveness of communication programs by an individual's functioning level.

\section{OTHER FINDINGS}

A statistical comparison was made between the subjects with the Transition Plan that include their communication needs and the subjects with the Transition Plan that do not include their communication needs regarding their Functioning Level scores. Figure 5 shows a bar graph of this comparison. A comparison was also made by using a T-Test. The Functioning scores mean of the subjects with the Transition Plans including their communication needs was 8.9 with a standard deviation of 2.7. The Functioning Score mean of the subjects with the Transition Plan that do not include their communication needs was 4.6 with a standard deviation of 3.0 . The subjects with the Transition plan including their communication needs had significantly higher Functioning score than the subjects with the Transition Plans that do not include their communication needs at $t(31)=3.93 ; p \leq .005$. This findings may indicate that the higher functioning subjects may have higher probability of having the Transition Plan that include their communication needs. 


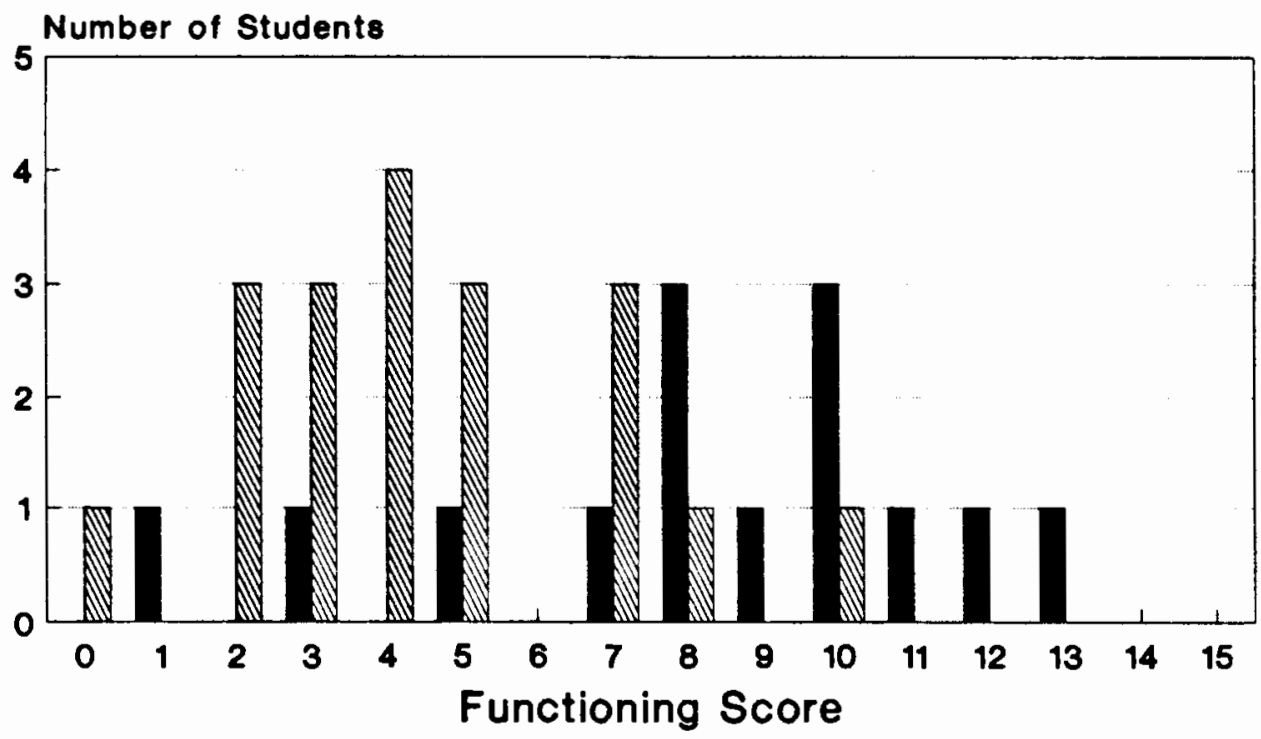

w/ Transition Plan w/o Transition Plan

Figure 5. Graph of Functioning Level and Transition Plan. 
CHAPTER VI

\section{DISCUSSION}

\section{EFFECTIVE COMMUNICATION PROGRAMS}

The results of this study indicate other interesting findings. First of all, there were some very interesting results in the effectiveness of communication programs. One of them was that 468 of subjects used their communication systems only for one function: requesting items and events. Also, 758 of subjects had a communication system that could not be understood by an unfamiliar person. Other interesting findings regarding the effectiveness of communication programs are as follows: 348 of the subjects used their communication systems only for activities in the special classroom; $30 \%$ of the subjects could not use their communication systems without prompting; $24 \%$ of the subjects did not initiate the use of the system in any place; and $34 \%$ of the subjects could not use the system spontaneously and consistently without the teacher/trainer cues in any place.

In spite of the support from previous research and studies, the results indicate that there is no significant impact on the effectiveness of communication programs by the degree of family involvement. However, there are some very interesting findings regarding family involvement. Eighty- 
five percent of the families did not communicate to the subjects by using their communication system, although $58 \%$ of them were living with their own family. Forty-five percent of the families contacted the teachers only once a month, while $21 \%$ of them did daily and $30 \%$ of them did weekly. Over all, two thirds of the subject's families were not involved in any way regarding the subject's communication needs.

Despite of a lack of significance by the subjects' communication modes, the results indicate some influence on the effectiveness of communication programs by them. The intelligibility of an augmentative communication system is the key factor to functioning in the community since this intelligibility is a measure of how much others can understand what a person means. The results indicate that $76 \%$ of the subjects were not understood by an unfamiliar person, and all of these subjects were using an unaided communication system. None of the subjects using aided augmentative communication system had difficulty being understood by an unfamiliar person.

As the results indicate, there was a significant influence on the effectiveness of communication programs by the subject's functioning level. At the same time, the subject's functioning level had great effects on the content of his or her Transition Plan. Higher functioning level subjects had more functional communication programs, as well as the Transition Plan including their communication needs. 
In other words, lower functioning level subjects had less chance to receive efficient and functional instruction in learning communication skills as compared with higher functioning level subjects. Although this matter has not been discussed in any previous study, it may not be any surprise, since it takes time to develop functional activities for lower functioning level individuals. During the interviews, some teachers mentioned that there are some difficulties in developing an augmentative communication system individually, because of the lack of time, and the number of students in the classroom. According to the initial survey in the reply sheet for the teachers, the speech-language pathologists came to the classroom once a week in all classrooms participating in this study. This lack of time may be one of the reasons that most lower functioning level individuals had less effective communication programs.

\section{STUDY LIMITATION}

The primary limitation with this study was the lack of a clear definition of a Transition Plan. This study was based on the assumption that all students with moderate to severe handicaps in high school would have Transition Plans. However, this was not always true. In the process of contacting the program supervisors, one of supervisors replied that her district could not participate in this study simply because they were in the process of developing a Transition 
Plan, and no student in high school had a Transition Plan yet. Most previous studies stressed that the initial Transition Plan should be developed by the time the student reaches age 12 , or at least four years prior to graduation from the secondary school system (Halpern, 1987; Wehman, Wood, Everson, Goodwyn, \& Conley, 1988; Sileo, Rude, \& Luckner, 1988; and Transition Committee on Visual Impaired, 1989). During the interviews, there were many students who did not have a Transition Plan yet. However, the survey in this study had only asked whether Transition Plans included the student's communication needs or not, and did not ask if each student had a Transition Plan.

Another limitation with this study was the lack of a measurement of reliability. Unfortunately, none of the instructional aides could participate in this study, so there was no information available regarding the reliability of the instruments. 
CHAPTER VII

CONCLUSION

\section{SUMMARY OF SUBJECTS AND METHODS}

Seven teachers in high school classrooms for students with moderate to severe handicaps participated in this study. These teachers selected a total of thirty-three students as subjects based on the criteria set by the chief investigator. Their age range was from thirteen to twenty-one. Fifty percent of the subjects were between age twenty and twentyone. Sixty-four percent of the subjects did not have any inclusion of their communication needs in their Transition Plans. Also, $63 \%$ of the subjects were described as lower functioning students who scored less than 8 points out of 15 points in the functioning scale. Forty percent of the subjects were using only gesture with or without vocalization to communicate with others.

The method used in this study was to interview seven teachers of high school students with moderate to severe handicaps about the students' communication programs and their Transition Plans. After the interviews, they filled out surveys for selected students as subjects for this study. In the process of interviewing, there were some difficulties in establishing the same understanding with the teachers about 
the operational definitions, especially concerning the Transition Plan. Actually, there were great differences between the school districts about the definitions, documentation, and contents of the Transition Plan as well as, the degree of the teacher's participation in developing the Transition Plan.

\section{SUMMARY OF RESULTS}

The results indicate a significant relationship between the effectiveness of communication programs and the inclusion of their communication needs in the Transition Plan. Higher Effectiveness Scores were earned by the subjects who have Transition Plans that include their communication needs. This may indicate that the Transition Plan has a positive influence to increase the effectiveness of communication programs.

Conversely, there was no significant impact on the effectiveness of communication programs by the individual's communication mode, or the degree of family involvement. However, the results indicate that there was a significant influence on the effectiveness of communication programs by the subject's functioning level.

\section{RECOMMENDATION}

As a recommendation for future studies, there may be a need to study more about existing Transition Plans, including their contained domains, documentation, the procedures used 
to develop them, and the starting age for their implementation. In addition to this, there may be a need to study how the student's functioning level has an effect on the development of functional communication programs, considering their communication modes. 


\section{REFERENCES}

AAMD ad hoc Committee on the Adaptive Behavior scale.

(1975). AAMD adaptive behavior scale for children and

adults. Washington, D.C.: American Association on

Mental Deficiency.

American Speech, Language and Hearing ad hoc Committee on Processes and Nonspeaking Persons. (1981). Position statement on nonspeech communication. ASHA, 23, $577-581$.

Bellamy, G. T., \& Horner, R. H. (1987). Beyond high school: residential and employment options after graduation. In M. E. Snell (3rd ed.). Systematic instruction of persons with severe handicaps (pp. 491-510). Columbus, OH: Merrill Publishing Company.

Charlson, F. (1981). A format for selecting vocabulary for the nonspeaking child. Language, speech and Hearing Services in Schools, 12, 240-245.

Everson, J. M. \& Moon, M. S. (1987). Transition services for young adults with severe disabilities. The Journal of the Association for Persons with Severe Handicaps, $\underline{12(2), 87-95}$.

Fairweather, J. S. (1989). Transition and other services for handicapped students in local education agencies. Exceptional Children, 55, 315-320.

Falvey, M. A. (1986). Community-based curriculum. Baltimore, MD: Paul H. Brookes Publishing Co.

Glennen, S. L., \& Calculator, S. N. (1985). Training functional communication board use: a pragmative approach. Augmentative and Alternative communication, 1, 134-141.

Halpern, A. S. (1987). Characteristics of a quality program. In C. L. Warger \& B. B. Weiner (Eds.), Secondary special education. (pp. 25-43). Reston, VA: The Council for Exceptional Children. 
Hardman, M. \& McDonnell, J. (1987). Implementing federal transition initiatives for youths with severe handicaps: the Utah community based transition projects. Exceptional Children, 53, 493-498.

Harris, D. (1982). Communicative interaction process involving nonvocal physical handicapped persons. Topic in Language Disorders, 2, 21-37.

Kaiser, A. P., Alpert, C. L., \& Warren, S. F. (1987). Teaching functional language: strategies for language intervention. In M. E. Snell (3rd ed.), Systematic instruction of persons with severe handicaps

(pp. 245-272). Columbus, OH: Merrill Publishing company.

Miller, J., \& Allaire, J. (1987). Augmentative communication. In M. E. Snell (3rd ed.), systematic instruction of persons with severe handicaps

(pp. 273-297). Columbus, OH: Merrill Publishing Company.

Mirenda, P. (1985). Designing pictorial communication systems for physically able-bodies students with severe handicaps. Augmentative and Alternative communication, $1,58-64$.

Mithaug, D. E., Martin, J. E., \& Agran, M. (1987). Adaptability instruction: the goal of transition programing. Exceptional Children, 53, 500-505.

Musselwhite, C. R., \& St. Louis, K. W. (1988). Communication programing for persons with severe handicaps: vocal and augmentative strategies (2nd ed.). Boston, MA: Little Brown \& Company.

Polloway, E. A., Patton, J. R., Payne, J. S., \& Payne, R. A. (1989). Strategies for teaching learners with special needs ( 4 th eds.). Columbus, OH: Merrill Publishing Company.

Reichle, J., \& Yoder, D. E. (1985). Communication board use in severely handicapped learners. Language, Speech and Hearing Services in Schools, 16(3), 146-157.

Rusch, F. R., Chadsey-Rusch, J., \& Lagomarichino, T. (1987). Preparing students for employments. In M. E. snell (3rd ed.), Systematic instruction of person with severe handicaps (pp. 471-490). Columbus, OH: Merrill Publishing Company. 
Russel, M. (1984). Assessment and intervention issues with nonspeaking child. Exceptional Children, 51(1), 64-71.

Shane, H., \& Bashir, A. (1980). Election criteria for determining candidacy for an augmentative communication system: preliminary consideration. Journal of Speech and Hearing Disorders, 45, 408-414.

Sileo, T. W., Rude, H.A., Luckner, J. L. (1988). Collaborative consultation: a model for transition planning for handicapped youth. Education \& Training in Mental Retardation, 23, 333-339.

Silverman, F. H. (1980). Communication for the speechless. Englewood cliffs, NJ: Prentice-Hall, Inc.

Stiea, T. M., \& Bauer, A. M. (1985). Parents and teachers of exceptional students. Newton, MA: Allyn and Bacon, Inc.

Transition Committee on Visual Impaired. (1989). Focus on the future: a transition guide for students with visual impairments. Salem, OR: Publications and Multimedia Center.

Warren, S. F. \& Roger-Warren, A. K. (1985). Teaching functional lanquage. Baltimore, MD: University Park Press.

Wehman, P., Wood, W., Everson, J. M., Goodwyn, R., \& Conley, S. (1988). Vocational education for multi handicapped youth with cerebral palsy. Baltimore, MD: Paul H. Brookes Publishing Co.

Wilkinson, L. (1989). SYSTAT: the system for statistics. Evanston, IL: SYSTAT, Inc. 
APPENDIX A

FUNCTIONING LEVEL SCALE 
HANDICAPPED CONDITIONS

Cerebral Palsy

- Cerebral Palsy

- in right side of body _ in upper body

- in left side of body $\quad$ in lower body

Mental Retardation

— mild severe/profound _ moderate

Hearing Impairment mild

L moderate

severe/profound

_ Visual Impairment mild moderate

_ severe/profound

RESIDENTIAL TYPE:

own home foster home

- $\begin{aligned} & \text { group home } \\ & \text { others }\end{aligned}$

(identify)

FUNCTIONING LEVEL SCALE:

1. The student feeds self with spoon and

fork.

YES NO

2. The student uses toilet without

assistance.

YES NO

3. The student walks alone or moves around without help.

YES NO

4. The student adds coins of various

denominations up to one dollar.

YES NO

5. The student counts objects up to ten. YES NO

6. The student makes minor purchases without help, e.g., candy, soft drink, etc.

YES NO

7. The student writes or prints own name

without help.

YES NO 
8. The student recognizes (reads or points out) at least then written words by sight.

YES NO

9. The student associates time on clock with various activities and events.

YES NO

10. The student will pay attention to purposeful activities at least 15 minutes.

YES NO

11. The student organize leisure time adequately on a simple level, e.g., watching T.V., listening to the radio, etc.

YES NO

12. The student indicates recognition of the names of people close to him when they are spoken, e.g., family members, etc.

YES NO

13. The student takes turn and shares objects with others.

YES NO

14. The student participates in the group activities.

YES NO

15. The student refrains from selfstimulation when he/she needs to stop.

YES NO 


\section{APPENDIX B}

FAMILY INVOLVEMENT \& COMMUNICATION MODE 
COMMUNICATION MODE:

1. Check one that apply the student's primary communication system: gesture with vocalization

- gesture without vocalization

- sign

oral speech with less than three sentences

- electric device with voice

- electric device without voice picture card

- communication board

- communication book

2. Check other systems that the student currently uses: gesture with vocalization gesture without vocalization sign oral speech with less than three-word sentences electric device with voice

- electric device without voice

- picture card

- communication board

- communication book

TRANSITION PLAN:

The student's Transition Plan includes his/her communication needs.

YES NO

FAMILY INVOLVEMENT:

1. The caregiver and/or student own the system.

YES NO

2. The caregiver selects vocabulary for the system.

YES NO

3. The caregiver can change vocabulary in the system easily.

YES NO

4. The caregiver can maintain the system

technically and economically.

YES NO

5. The caregiver uses the system to communicate with the student. 
6. The caregiver and the teacher exchange and share information:

$$
\text { daily }
$$

weekly monthly

- once every other month

_ only at IEP meeting 


\section{APPENDIX C}

\section{COMMUNICATION EFFECTIVENESS SCALE}


COMMUNICATION EFFECTIVENESS SCALE:

1. Unfamiliar person (stranger) can understand what the student means when he/she uses his/her communication system. YES NO

2. The student operates the system without assistance.

YES NO

3. The student carries the system without assistance.

YES NO

- Check all sites where the student uses the communication system:
4 . activities in the special classroom
5. - integrated activities outside of special classroom
6. activities in the community
7. - vocational training in the classroom and school
8. - vocational training in the community
9. - home

- The student uses the system without prompting to communicate with: (check all that apply)
10 .
11 . special education teacher
12. instructional aides
13. peer tutors
14. - other peers in his/her classroom
15. - others in the school
16. vocational trainer/supervisor
17. - co-workers at work site
18. - family members
19. - friends
20. - familiar people in the community
21. - unfamiliar people (stranger)

- The student initiates the use of the system in: (check all that apply)
22 .
23 .
special classroom
24 .
other places in the school
25 . work site
25. home
26.
familiar places in the community
27. new places in the community 
- The student uses the system spontaneously and consistently without cues from the teacher/trainer in: (check all that apply) 28.

29. - other places in the school

30. work site

31. home

32. - familiar places in the community

33. - new places in the community

- The student uses the system to: (Check all that apply)

34 . request items and events

35. — reject and/or protest

36. - ask questions

37. state comments

38. - get information

39. - express feeling and thought 
APPENDIX D

IETTERS TO PROGRAM SUPERVISORS 
To Special Education Supervisor:

My name is Yuki Tanaka, a graduate student in special education at Portland State University. Currently, I am working on my master's thesis, looking at relationships between the Transition Plan and the effectiveness of the student's communication programs. My study will involve an interview and survey procedures with teachers and aides in high school classrooms for individuals who have oral speech with less than three-word sentences and/or use an augmentative communication system. I am interested in an individual's communication system, communication programs, family involvement, and Transition Plan.

I will be scheduling surveys to occur during the month of March. I will need to spend 30-45 minutes with each teacher and/or aide during one interview session. I would greatly appreciate your assistance in identifying teachers and aides to participate in this study, and by arranging permission to interview them. Also, if possible, I would like to review some students' programs and Transition Plans. I enclosed a sample of the survey sheet and a letter for teachers. I would like you to fill out the attached sheet with requested information and return it to me in the enclosed envelope no later than January. Thank you for your cooperation.

sincerely,

Yuki Tanaka 


\section{REPLY SHEET}

NAME :

DISTRICT NAME:

I will permit you to contact teachers in high school classroom.

YES NO

I will permit you to contact aides in high school classroom.

YES NO

I will permit you to review students' communication programs.

I will permit you to review students' Transition Plans.

If you permit me to contact teachers/aides, please write down their names, schools, addresses, and telephone numbers.

If you have any comments, please write down.

Thank you for your help. 
APPENDIX E

LETTER TO TEACHERS 
To Special Education Teacher:

My name is Yuki Tanaka, a graduate student in special education at Portland State University. Currently, I am working on my master's thesis regarding the Transition Plan and the effectiveness of students' communication programs. My study will involve an interview and survey procedures with teachers in high school classrooms. Therefore, I would like you to voluntarily participate in my study.

This is what is involved:

1. I will contact with you to set an appointment for us to meet for approximately 30 minutes. My schedule is very flexible, so I am willing to work around yours. 2. You will need to have students' communication programs on hands to discuss. I am not interested in a $n y$ student's names, I am interested in their communication systems and activities that you use to teach communication. 3. After reviewing communication programs, I will give you a survey sheet for each student who we selected during the interview. These surveys will then be filled out by you and returned to me by mail. Your name, school or district will not be cited by name in the study, nor will any information be cited regarding students.

I am hoping you will assist me in this study. Please fill out the attached sheet and return to me in the enclosed envelope as soon as possible. Thank you.

sincerely,

Yuki Tanaka 
REPLY SHEET

NAME :

SCHOOL:

I will participate in your study.

YES NO

If you circle "yes", please answer the following initial survey, too.

1. How may student are having oral speech with less than three-word sentences and/or use an augmentative communication system?

2. How often does the speech-language pathologist come to your classroom?

3. How many instructional aides do you have in your classroom?

4. Check one that describes your teaching certification:

_ Handicapped Learner _ _ Visually Impaired

_ Severely Handicapped Learner

- other $\frac{}{\text { (identify) }}$

If you have any comments, please write down.

Thank you for your cooperation. 
APPENDIX $\mathbf{F}$

INFORMED CONSENT FORM 
I,

hereby agree to serve as a subjects in the research project on the influence of the Transition Plan in developing communication programs conducted by Yuki Tanaka.

I understand that the study involve the student's communication programs, Transition Plan, communication modes, and family involvement regarding their communication systems.

I understand that possible risk to me associated with this study is demand on my time.

It has been explained to me that the purpose of the study is to learn the relationship between the Transition Plan and the effectiveness of communication programs, considering the student's functioning level, family involvement, and the contents of the student's communication system.

I will not receive any direct benefit from participation in this study, but my participation may help to increase knowledge that may benefit others in the future.

Yuki Tanaka has offered to answer any questions I may have about the study and what is expected of me in the study. I have been assured that all information I give will be kept confidential and neither my name nor identity will be used for publication or public discussion purposes.

I understand that I am free to withdraw from participation in this study at any time without jeopardizing my relationship with Portland State University.

I have read and understood the foregoing information and agree to participate in this study.

DATE

SIGNATURE

If you experience problems that are the result of your participation in this study, please contact the Chair of the Human subjects Research Review Committee, Office of Grants and Contracts, 303 Cramer Hall, Portland State University, 725-3417. 